\title{
Comparative Study on Compressive Strength of Concrete with New Sand-Cap and Neoprene Pad
}

\author{
Young-Shik Park' ${ }^{1)}$ and Jin-Kook Suh ${ }^{2)}$
}

(Received April 24, 2007, Revised October 2, 2007, Accepted November 6, 2007)

\begin{abstract}
The most typical capping method for concrete structures is a sulfur-mortar compound capping, provided it satisfied the standard criterion set forth by ASTM C 617, but this conventional bonded-type method has many problems. It exhibits relatively the smaller unreliable value of the strength of high-strength concrete due to the differences of elasticity and strength between the cylinder and the cap, and manifests poor serviceability such as dangerous working tasks or a waste of the working time. To prevent these problems, unbonded-type capping methods have taken the place of the conventional methods in recent years. One of the popular methods is the use of synthetic rubber like a neoprene pad. Serious problems still remain in this method, which include the consideration of its chemical characteristics in consideration of the selection, the safekeeping and the economy of the pads. Moreover, the synthetic rubber pads cannot be used in concrete cylinder with strength greater than $80 \mathrm{MPa}$ according to ASTM C 1231-00. New 'sand-capping method' presented in this study, can be applicable to the compressive strength evaluation of the high strength concrete in the range of $70 \sim 100 \mathrm{MPa}$. This new method has better simplicity and reliability than those of existing 'sand-box', because usual materials such as standard sand and simply-devised apparatus are used for the capping system. The statistical analysis of the test results revealed that the new sand-capping method exhibited the smallest deviation and dispersion, attesting for its much better reliability than other methods specified in ASTM C 1231/1231M.
\end{abstract}

Keywords: capping, sand-cap, neoprene pad, compressive strength, high strength concrete.

\section{Introduction}

Various errors in measuring compressive strength of concrete tend to be due to the test method and condition. Thus, capping at the end of concrete cylinder should satisfy the specific standards set forth in ASTM C $617^{1}$ in order to obtain accurate test results for the compressive strength of concrete. Of a particularly important concern in the case of high strength concrete cylinder is that the reliable data on itscompressive strength can be measured only by a special end-capping method. The method of cutting and grinding the end of a cylinder is employed in the compression test of high strength concrete, because the compressive strength test by conventional bonded-type methods using a cap with sulfur-mortar, high-strength mortar or high-strength gypsum has shown relatively the smaller unreliable values of the compressive strength. Unbonded capping methods such as grinding or capping with pads is not efficient in economical administration and easy administration of the test as well.

New 'sand-capping method', which is introduced in this study, uses a simpler device compared to other complicated 'sand-box' system proposed by Purington and $\mathrm{McCormick}^{2}$ or Boulay and

\footnotetext{
${ }^{1)} \mathrm{KCI}$ member, Dept. of Civil Engineering, Kundong University, Andong760-833 Korea.E-mail: blue85888@naver.com

${ }^{2}$ Dept. of Civil Engineering, Kyungdong College, Kyungsan 712904, Korea.

Copyright (c) 2008, Korea Concrete Institute. All rights reserved, including the making of copies without the written permission of the copyright proprietors.
}

Larrard. ${ }^{3}$ It is to be shown that this new capping system is not only more economical in terms of the test time and process but more reliable in the test results than any other unbonded method. These results are verified by the average compressive strength of concrete as compared to sand-capping, neoprene pad capping and sulfurmortar capping methods pursuant to ASTM C 1231/1231 M. ${ }^{4}$

\section{Experimental programs}

In this study, the effect of capping method for concrete cylinderend only is considered in the evaluation of its compressive strength. The other testing factors such as specimen size, loading method, testing-machine type etc. should follow the specifications of ASTM C 39. ${ }^{5}$ Such three capping methods are sulfur-mortar compound capping, neoprene pad capping and sand capping. The design strength for each concrete cylinder group is set to be $21 \mathrm{MPa}$ (Group A), $34 \mathrm{MPa}$ (Group B) and $70 \mathrm{MPa}$ (Group C) subjected to the following mix proportions.

\subsection{Test specimens}

The three mix proportions as shown in Table 1 were prepared to investigate the effect of capping on the compressive strength, and cylindrical specimens of $\varnothing 100 \mathrm{~mm} \times \mathrm{H} 200 \mathrm{~mm}$ were cast by moulds. The test groups were composed of 20 specimens for each mix type and each capping method. Ordinary Portland cement (ASTM type I) was used for all the specimens. Crushed stone with $19 \mathrm{~mm}$ maximum size and river sand were used as the coarse and fine aggregate, respectively. Powdered silica-fume was used as an 
Table 1 Mix proportions of concrete cylinders.

\begin{tabular}{c|c|c|c}
\hline \multirow{2}{*}{ Specimen group } & \multicolumn{3}{|c}{ Batch weight } \\
\cline { 2 - 4 } & Group A & Group B & Group C \\
\hline \hline $\mathrm{W} / \mathrm{b}$ & 0.53 & 0.37 & 0.28 \\
\hline Cement $\left(\mathrm{kg} / \mathrm{m}^{3}\right)$ & 321 & 490 & 520 \\
\hline Water $\left(\mathrm{kg} / \mathrm{m}^{3}\right)$ & 171 & 181.3 & 147 \\
\hline Fine aggregate $\left(\mathrm{kg} / \mathrm{m}^{3}\right)$ & 905 & 683 & 634.6 \\
\hline Coarse aggregate $\left(\mathrm{kg} / \mathrm{m}^{3}\right)$ & 945 & 982 & 1128.4 \\
\hline Superplasticizer $(\%)$ & 0.5 & 0.8 & 2.0 \\
\hline Silica-fume $(\%)$ & 0 & 0 & 10 \\
\hline Slump $(\mathrm{mm})$ & 120 & 80 & 60 \\
\hline Compressive strength at 28 days $(\mathrm{MPa})$ & 21 & 34 & 70 \\
\hline
\end{tabular}

admixture for the high strength concrete in this test. All the materials were mixed a concrete pan mixer of 80 liter capacity. The compression test of concrete cylinder was performed after the aging of 90 days passed by in consideration of the differences in the making and curing days. The curing of all specimens was performed in water until the aging of 28 days.

\subsection{Capping methods}

Three kinds of capping methods were used to compare the compressive strength of each specimen in this study. Molten sulfur-mortar compound capping was formed by a vertical capping apparatus as specified in ASTM C 617, and neoprene pad for an unbonded capping system was employed to test the hardened concrete cylinders in accordance with the capping standards as described in ASTM C 1231/ C 1231M. An elastomeric pad like neoprene pad deforms upon initial loading, conforming to the contour of the cylinder-end, and it is restrained from excessive lateral spreading by its plate and metal ring to provide a uniform distribution of the load exerting from the bearing blocks of testing machine to the end of concrete cylinder. The sand capping method as suggested in this study has the cylinder placed only on the top of sand as a simple capping device, without any other sealing process or sub-device of the existing sand-box systems. All of the dry and fine sand was passed through No.20 sieve for its use as a sand capping material.

The average thickness of the caps is summarized in Table 2 for the selection of objects of a statistical analysis. The compression test of concrete cylinders was performed for the three cylinders per each capping method in sequence in order to control for the influence of eccentricity error caused by the testing machine. The weight of sand in the device was measured at just 0.1g-precision because of the difficulty in taking an accurate measurement of the cap-thickness. Dimensions of sand-capping system and neoprene pad ring are shown in Fig. 3 and the attached table.
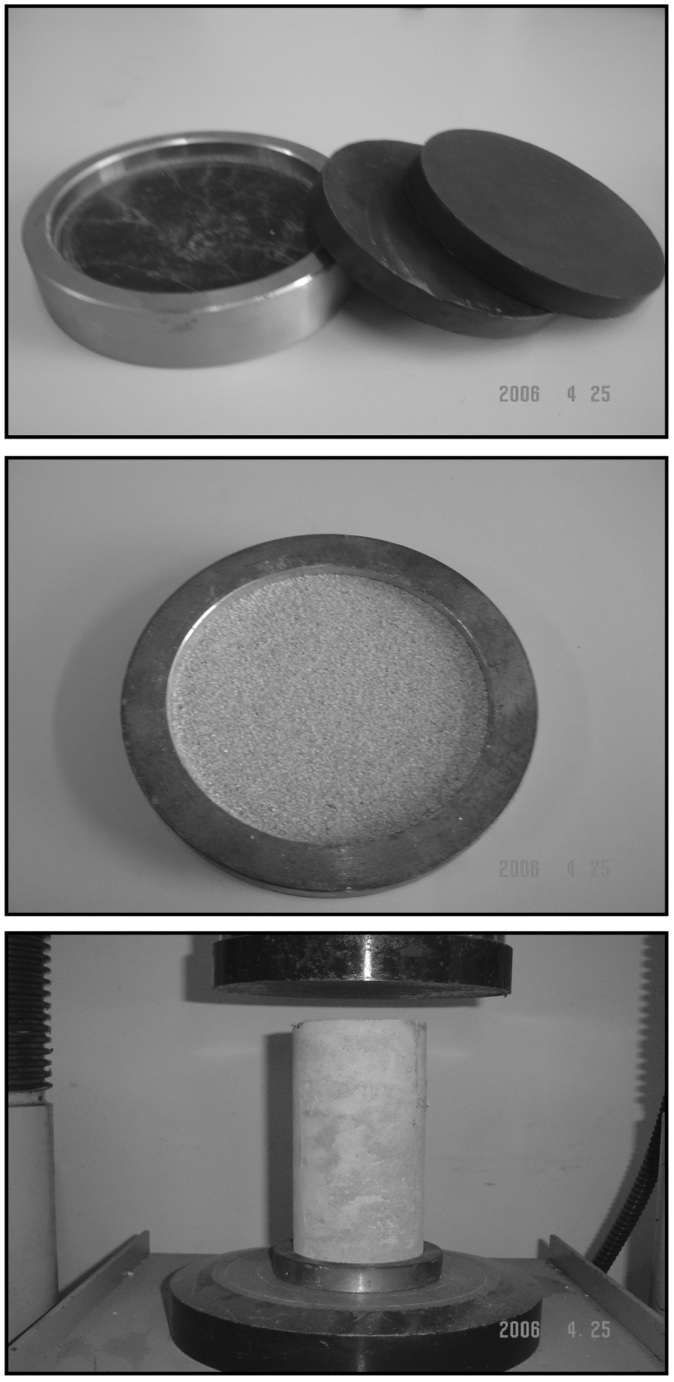

Fig. 1 Sand-capping system and neoprene pad ring.

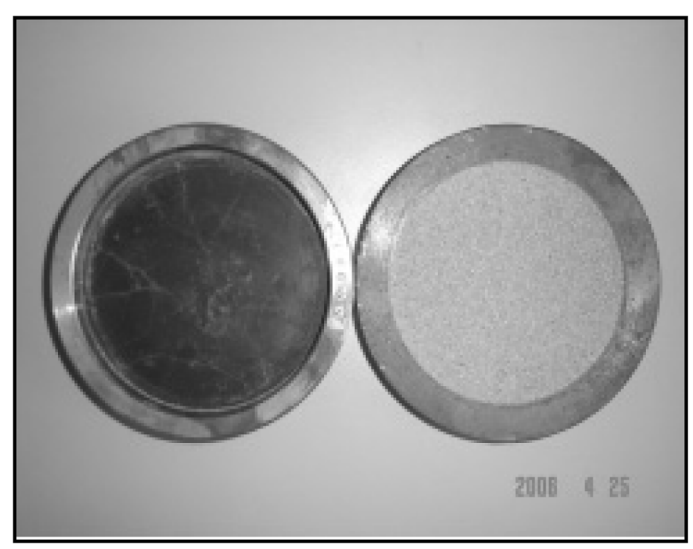

Fig. 2 Post-testing status of neoprene pad and sand cap (hardening of neoprene pad).

Table 2 Thickness of cap.

\begin{tabular}{c|c|c|c}
\hline Types of cap & Average thickness & Retainer ring & Mixture of cap materials \\
\hline \hline Unbonded neoprene \& natural pads & $12.8 \mathrm{~mm}$ & $102 \mathrm{~mm} \times 254 \mathrm{~mm}$ & Neoprene \& natural rubbers/ steel \& aluminum alloys \\
\hline Sulfur-mortar compound cap & $2.4 \mathrm{~mm}$ & - & Sulfur compound \\
\hline Sand cap & $38 \mathrm{gr}$ & $101.1 \mathrm{~mm} \times 10 \mathrm{~mm}$ & Fine sand/ steel \& aluminum alloys \\
\hline
\end{tabular}




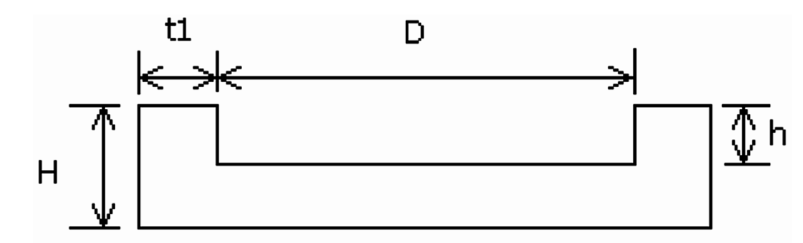

\begin{tabular}{c|c|c|c|c|c}
\hline & $\begin{array}{c}\text { Specimen } \\
(\mathrm{mm})\end{array}$ & $\mathrm{D}$ & $\mathrm{H}$ & $\mathrm{t} 1$ & $\mathrm{~h}$ \\
\hline Neoprene pad ring & $\varnothing 100 \times 200$ & $105 \pm 1$ & $35.4 \pm 1$ & $11 \pm 1$ & $25.4 \pm 1$ \\
\hline $\begin{array}{c}\text { Sand-capping } \\
\text { system }\end{array}$ & $\varnothing 100 \times 200$ & $101.1 \pm 0.5$ & $22 \pm 1$ & $15 \pm 1$ & $10 \pm 1$ \\
\hline
\end{tabular}

Fig. 3 Dimensions of sand-capping system and neoprene pad ring.

\section{Results and discussion}

\subsection{Verification of test results}

The test results were sampled to investigate the compressive strength of the test cylinders except for underrated (outlier) data due to excessive cap-thickness, imperfect capping, or failure caused by eccentric loading. The statistical confidence level of $95 \%$ was set so that the results are to be statistically acceptable at $\alpha=0.05$. The average compressive strength obtained by unbonded capping should not be less than $98 \%$ of that obtained by bonded capping or grinding methods pursuant to ASTM C 1231.

The calculation process for verifying the unbonded capping system involved the following. For every strength group, the difference in strengths of each pair of cylinders ('sulfur-mortar capped cylinders vs. neoprene pad capped cylinders' or 'sulfurmortar capped cylinders vs. sand capped cylinders') was computed. Next, it was verified that the average strengths of the two kinds of unbonded capping cylinders were over $98 \%$ of those of sulfurmortar capping cylinders.

$$
\begin{aligned}
& d_{i}=x_{p i}-x_{s i} \\
& x_{s}=\left(x_{s 1}+x_{s 2}+x_{s 3} \cdots x_{s n}\right) / n \\
& \mathrm{x}_{\mathrm{p}}=\left(x_{p 1}+x_{p 2}+x_{p 3} \cdots x_{p n}\right) / n
\end{aligned}
$$

where,

$d_{i}$ : Difference in strength of a pair of cylinders according to ASTM C 617.

$x_{p i}:$ Cylinder strength using unbonded capping.

$x_{s i}:$ Cylinder strength using Practice for ASTM C 617.

$n$ : Number of the combination of the cylinder pairs tested for the strength comparison.

$x_{s}$ : Average strength of cylinders for each Group according to practice for ASTM C 617.

$x_{p}$ : Average strength of the unbonded capping cylinders for each Group.

average difference, $d=\left(d_{1}+d_{2}+d_{3} \cdots d_{n}\right) / n$ standard deviation, $s_{d}=\left[\Sigma\left(d_{i}-d\right)^{2} /(n-1)\right]^{1 / 2}$

In order to comply with the Practice for ASTM C 617, the following relationship must be satisfied,

$$
x_{p} \geq 0.98 x_{s}+\left(t \cdot S_{d}\right) /(n)^{1 / 2}
$$

where, $t$ is the value of 'student's $t$-test' for $(n-1)$ pairs at significance level of $\alpha=0.05$ as shown in the following table:

\begin{tabular}{c|c}
\hline$(' n-1)$ & $t(\alpha=0.05)^{*}$ \\
\hline \hline 9 & 1.833 \\
\hline 14 & 1.761 \\
\hline 19 & 1.729 \\
\hline 100 & 1.662 \\
\hline
\end{tabular}

"Use linear interpolation for other values of $(n-1)$ or refer to appropriate statistical tables.

The calculation process and results are shown in Table 3 for the verification of the test result. All the compressive strengths of cylinders by unbonded capping methods exhibited greater than $98 \%$ of the reference values for all Group A, B and C.

\subsection{Analysis of test results}

\begin{tabular}{|c|c|c|c|c|}
\hline Capping types & Calculations (MPa) & Group A & Group B & Group C \\
\hline \multirow{6}{*}{$\begin{array}{l}\text { Neoprene pad vs. } \\
\text { Sulfur-mortar capping }\end{array}$} & (1) $x_{p}$ & 21.75 & 35.42 & 79.02 \\
\hline & $x_{s}$ & 21.6 & 35.12 & 76.91 \\
\hline & $d$ & 0.15 & 0.305 & 2.115 \\
\hline & $s_{d}$ & 0.6977 & 1.6599 & 3.6881 \\
\hline & (2) $0.98 x_{s}+\left(t \cdot s_{d}\right) /(n)^{1 / 2}$ & 21.44 & 35.07 & 76.83 \\
\hline & System qualifies (1) $\geq$ (2) & O.K & O.K & O.K \\
\hline \multirow{6}{*}{$\begin{array}{l}\text { Sand capping vs. } \\
\text { Sulfur-mortar capping }\end{array}$} & (1) $x_{p}$ & 22.28 & 36.8 & 81.09 \\
\hline & $x_{s}$ & 21.6 & 35.12 & 76.91 \\
\hline & $d$ & 0.68 & 1.685 & 4.185 \\
\hline & $s_{d}$ & 0.7516 & 1.6769 & 2.3640 \\
\hline & (2) $0.98 x_{s}+\left(t \cdot s_{d}\right) /(n)^{1 / 2}$ & 21.47 & 35.08 & 76.30 \\
\hline & System qualifies (1) $\geq$ (2)? & O.K & O.K & O.K \\
\hline Common details & $n=20, t=1.729$ & & & \\
\hline
\end{tabular}

In the statistical analysis of test results, the compressive strengths of cylinders by neoprene-pad capping manifested the

Table 3 Verification process of test results. 
smallest values of deviation and dispersion for normal strength concrete, but those by sand-capping method exhibited the least deviation and dispersion for high strength concrete. The average strengths of cylinders by sand-capping method are shown as the highest values of all Groups in Table 4.

The compressive strengths of the test specimens prepared by sulfur-mortar capping, neoprene pad capping and sand capping for Groups A, B and C in the range of $20 \mathrm{MPa} 80 \mathrm{MPa}$ are shown in (a), (b), (c) of Fig. 4. A point on the graph indicates the compressive strength for one cylinder. The variation of average

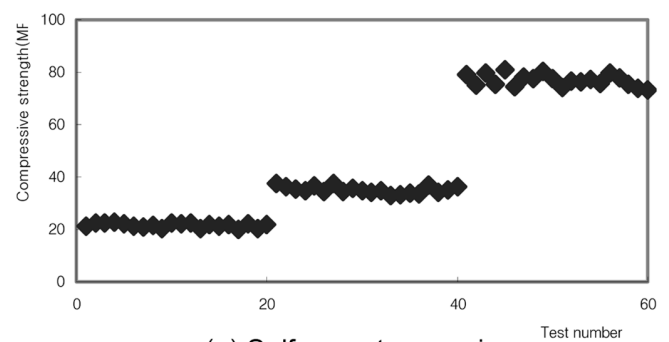

(a) Sulfur mortar capping

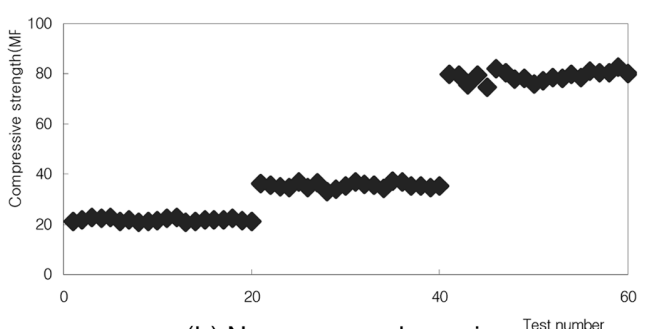

(b) Neoprene pad capping Test number

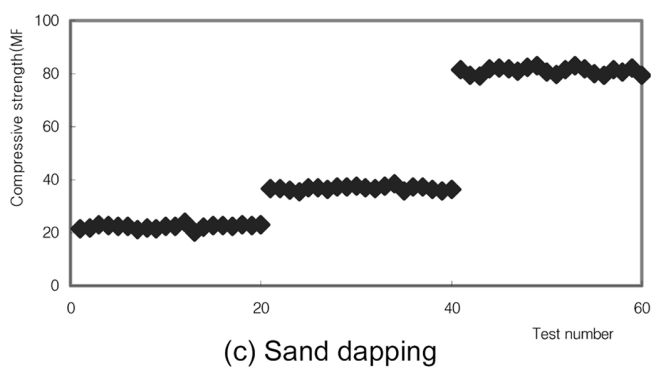

Fig. 4 Compressive strengths of cylinders prepared by three capping methods. compressive strengths for each capping method is shown in Fig. 5(a).

In Fig. 5(a), the comparison of compressive strengths of cylinders prepared by neoprene pad capping and sulfur mortar capping reveals a little difference in the lower strength level, Group A and B, but the difference in the strengths of $27 \%$ is observed in Group C. As the concrete strength gets higher, the more difference in the strength by the capping methods is observed. The compressive strengths of concrete prepared by sand capping method are 3 5.4\% higher than those prepared by sulfur mortar capping, and the difference in the strengths of the concrete increases more in the concrete of higher strength level. When the compressive strength of cylinder prepared by sulfur mortar capping is set to 1 as a reference value, the relative values of the strength of the concrete prepared by unbonded capping methods are shown as a ratio relative to it in Fig. 5(b). The standard deviations and the dispersions of the compressive strengths in Fig. 5(c) and 5(d) are greater for the higher strength level, Group C. The smallest value of deviation and dispersion is observed in the test specimens prepared by sand capping method.

The test for the compressive strength of concrete cylinder specimens revealed that the relatively higher strength concrete did not exhibit a proper strength value for a concrete cylinder, instead it was rather overestimated. Thus, a proper estimation of the compressive strength of a concrete cylinder can only be proven by reliable test results as for the case of smaller deviation and dispersion.

\section{Conclusions}

This study found that the strength of a concrete cylinder was obviously affected by different capping methods, and the effect increased significantly as the strength level of the concrete cylinder was higher. Strength variation due to various capping methods exhibited a different tendency for normal and high strength concrete cylinders.

The standard deviation and the dispersion of strength for sandcapped cylinders were less than those of sulfur-mortar or neoprene pad capped cylinders. Thus, sand-capping method was the most reliable in consideration of the standard deviation and dispersion

Table 4 Statistical analysis of test results.

\begin{tabular}{|c|c|c|c|c|}
\hline Capping types & Analysis of results & Group A & Group B & Group C \\
\hline \multirow{4}{*}{ Sulfur-mortar capping } & Average strength (MPa) & 21.6 & 35.1 & 76.9 \\
\hline & Standard deviation & 0.86 & 1.37 & 2.27 \\
\hline & Dispersion & 0.75 & 1.87 & 5.14 \\
\hline & No. of specimens & 20 & 20 & 20 \\
\hline \multirow{4}{*}{ Unbonded neoprene pad capping } & Average strength $(\mathrm{MPa})$ & 21.75 & 35.4 & 79.2 \\
\hline & Standard deviation & 0.63 & 1.11 & 2.06 \\
\hline & Dispersion & 0.4 & 1.23 & 4.23 \\
\hline & No. of specimens & 20 & 20 & 20 \\
\hline \multirow{4}{*}{ Sand capping } & Average strength (MPa) & 22.28 & 36.8 & 81.1 \\
\hline & Standard deviation & 0.75 & 0.73 & 1.23 \\
\hline & Dispersion & 0.56 & 0.53 & 1.49 \\
\hline & No. of specimens & 20 & 20 & 20 \\
\hline
\end{tabular}




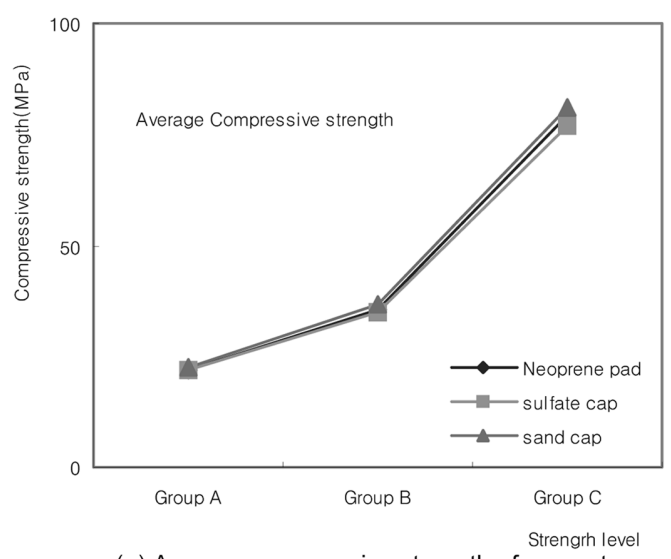

(a) Average compressive strength of concrete

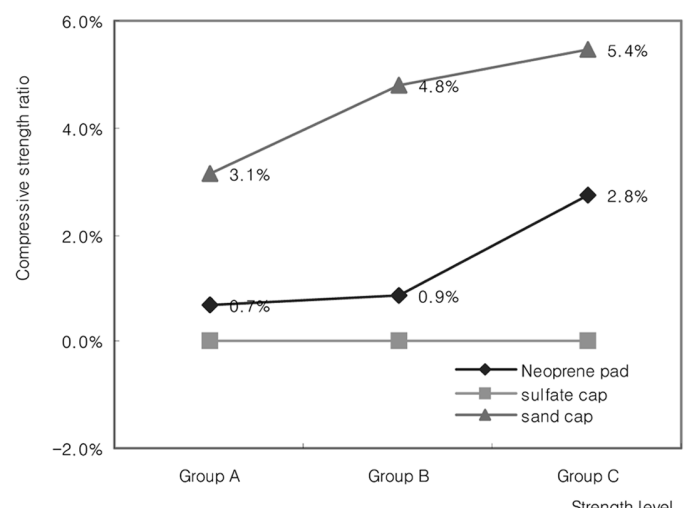

(b) Ratio of compressive strength

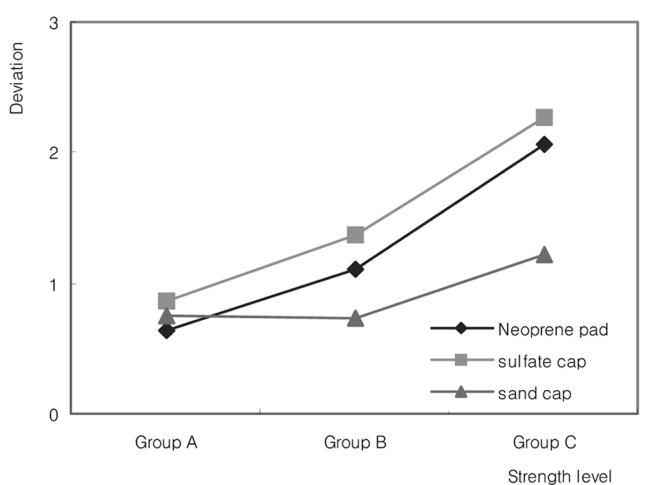

(c) Standard deviatio

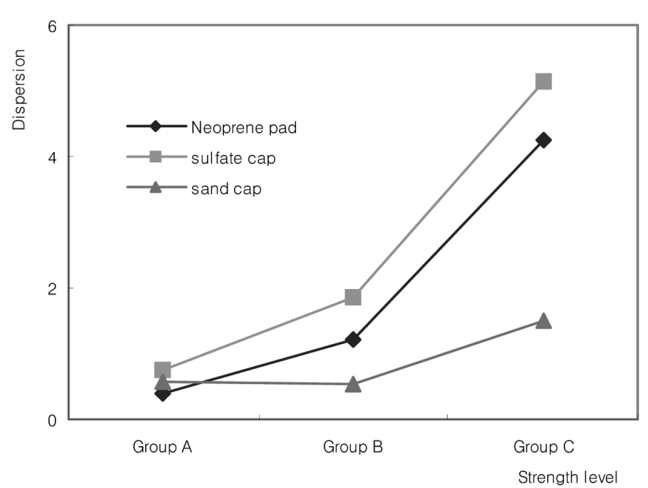

(d) Dispersion of strength when every capping methods were analyzed statistically.

Thus, conventional bonded-capping methods might be improper for the compressive test of high strength concrete. Additionally, unbonded neoprene pad capping was not satisfactory in estimating the compressive strengths of high strength concrete, for it was not competitive to sand capping system in terms of the economy and the simplicity of the test.

Consequently, the general use of new sand capping system is proposed in this study to estimate the compressive strengths of both normal and high strength concrete cylinder more reliably and accurately.

\section{References}

1. ASTM, "Standard Practice for Capping Cylindrical Concrete Specimens (ASTM C 617)," Anmual Book of ASTM Standards, Vol. 04.02, ASTM, Philadelphia, 2000, pp. 380 384.

2. Purington, W. F. and McCormick, J., "A Simple Device to Obviate Capping of Concrete Specimens," ASTM Proceedings, Vol. 26, Part, 1926, pp. 488 492.

3. Boulay, C. and de Larrard, F., "The Sand-Box," Concrete International, Vol. 15, No. 4, April, 1993, pp. 63-66.

4. ASTM, "Standard Practice for Use of Unbonded Caps in Determination of Compressive Strength of Hardened Concrete Cylinders (ASTM C 1231/ C1231M-00)," Anmual Book of ASTM Standards, 2000.

5. ASTM, "Standard Test Method for Compressive Strength of Cylindrical Concrete Specimens (ASTM C 39)," Anmual Book of ASTM Standards, ASTM, Philadelphia, Vol. 04.02, 2000, pp. 24 29.

6. ASTM, "Standard Method of Making and Curing Concrete Test Specimens in the Field (ASTM C 31)," Anmual Book of ASTM Standards, ASTM, Philadelphia, Vol. 04.02, 2000, pp. 5 10.6.

Fig. 5 Statistical analysis of test analysis. 